\title{
Study of the use of nanomaterials as drilling mud additives
}

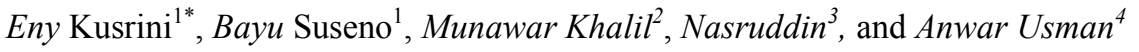 \\ ${ }^{1}$ Department of Chemical Engineering, Faculty of Engineering, Universitas Indonesia, Kampus Baru UI Depok, 16424, \\ Indonesia \\ 2 Faculty of Mathematic and Natural Sciences, Universitas Indonesia, Kampus Baru UI, Depok 16424. \\ ${ }^{3}$ Department of Mechanical Engineering, Faculty of Engineering, Universitas Indonesia, Kampus Baru UI Depok, 16424, \\ Indonesia \\ ${ }^{4}$ Department of Chemistry, Faculty of Science, Universiti Brunei Darussalam, Jalan Tungku Link, Gadong BE1410, Negara \\ Brunei Darussalam
}

\begin{abstract}
Previous research on drilling mud concludes that oil-based mud is the best drilling fluid, but is not recommended because it is unsustainable and environmentally unfriendly. Therefore, research has been conducted on additives that can be used for water-based mud, making it equal or even superior in quality to oil-based mud. The use of graphene as a drilling mud additive may form mud cake as a filtration barrier, and the use of magnesium oxide $(\mathrm{MgO})$ may increase the viscosity value. Rheological analysis is conducted using the Bingham plastic method, a simple method generally used in the oil and gas fields, whereas use of the Power Law model can provide better modelling of Bingham plastic that cannot be achieved for well under surface analysis. Tension limit simulation was performed to determine the safe limits of the tool's ability to withstand loads. Control of equivalent circulation density (ECD) is very important; if this is too high it can cause loss of circulation, and if too low it can cause kick. In Bingham plastic, the value of plastic viscosity and the yield strength of the graphene additive increased by 25 and $32 \%$, respectively, compared to the base formula. The $\mathrm{MgO}$ yield strength value is too high, indicating that $\mathrm{MgO}$ cannot be used as a drilling mud fluid additive. In graphene oxide (GO) additives, there is a decrease in plastic viscosity of $50 \%$ and an increase in yield strength of up $180 \%$. The graphene torque limit value increased by $0.2 \%$ and the drilling depth increased by $2.8 \%$ compared to the base formula. The GO torque limit value increased by $0.2 \%$ and the drilling depth increased by $2.08 \%$ from the base formula, while the tension limit of the graphene additive increased by $38.8 \%$ from the base formula and on the GO decreased by $2.11 \%$. From the ECD simulation, graphene is more suitable for wells with high formation pressures, GO is more suitable for low pressure wells.
\end{abstract}

\section{Introduction}

Drilling mud is one of the most important factors in drilling operations [1]. In addition to its function to facilitate circulation during drilling, it has several other functions that are no less important, namely lifting cutting drilling to the surface; coolling and lubricating the chisel and drill string; preventing corrosion; lining the wall of the borehole with mud cake; controlling formation pressure; restraining cutting when circulation has stopped; in the introduction of hydraulics; as an information medium and media logging; and retaining some of the heavy drill pipe and casing.

In the industrial world, bentonite is known as a clay derived from the smectite mineral group [2]. It was originally known as montmorillonite and is still widely referred to by this name in the petroleum industry. In this industry, bentonite serves as a material to increase viscosity, which is also known as a viscosifier.

In order to have properties appropriate for the conditions found in drilled wells, drilling mud usually contains additives. These comprise several types, including ones for fluid loss control; thinner; weighting material; lost circulation material; and some drilling mud additives used in oil-based mud. The use of existing additives does not have a significant impact on improving the quality of waterbased mud in drilling compared to oil-based mud. Therefore, research on additives as drilling mud fluids has led to the possibility of the use of nanomaterials. This is because nanomaterials show wide-ranging potential that can be developed and also possess the properties required by water-based mud to be superior to oil-based mud. Some of the nanoparticles that have the potential to serve as additives to drilling fluids are graphene, graphene

Corresponding author: ekusrini@che.ui.ac.id 
oxide $(\mathrm{GO}),[3,4]$ and magnesium oxide $(\mathrm{MgO})$ [5, $6]$.

The use of graphene as a drilling mud fluid additive is possible because it has a special surface area of $2,965 \mathrm{~m}^{2} / \mathrm{g}$; it acts as a strong penetrating membrane layer that is not opaque even helium gas. This can make the formation of mud cake in drilling mud stronger, so it can prevent the mud flooding into the formation. However, large graphene-cut distributions in the water environment sometimes experience problems with water-based drilling muds. Therefore, scientists recommend using graphene oxide (GO), which is more water resistant and has the same layered morphology to be able to form the desired mud cake. In addition, GO has another interesting characteristic, namely separation of the solution and the formation of a strong paper-shaped material capable of efficiently preventing drilling mud leaks to the well wall [4].

Magnesium oxide $(\mathrm{MgO})$ can be produced from calcining magnesium carbonate at a temperature of $700-1000^{\circ} \mathrm{C}$, while hard burnt magnesia with an average surface area of $0.1-1.0 \mathrm{~m}^{2} / \mathrm{g}$ produced at temperatures of $1100^{\circ} \mathrm{C}-1650^{\circ} \mathrm{C}$ and applied to the feed livestock and fertilizer. Meanwhile, dead burn of magnesia by calcination at a temperature of $1450^{\circ} \mathrm{C}$ $2200^{\circ} \mathrm{C}$ and surface area of $0.1 \mathrm{~m}^{2} / \mathrm{g}-250 \mathrm{~m}^{2} / \mathrm{g}$ and can be applied in the petroleum industry [7]. An example is a thickened bentonite suspension with $\mathrm{MgO}$ for the preparation of drilling mud; the addition of $\mathrm{MgO}$ to the suspension significantly increases the viscosity of the bentonite suspension, while in the case of calcium and mixed bentonite activation with $\mathrm{MgO}$, early soda activation is required [8]. In addition, it has been reported that among the $\mathrm{MgO}-$ only magnesium-based additives with very low dissolution rates regulating the viscosity behaviour of clay suspensions and others such as $\mathrm{MgCO}_{3}$, $\mathrm{Mg}(\mathrm{OH})_{2}$ and $\mathrm{MgCl}_{2}$ do not work properly [9].

Graphene can increase the bit age range by up to $75 \%$ and reduce the use of polymers by up to $40 \%$ in the mud planning formula [10]. MgO can increase the gel strength value by up to $92 \%$ and increase the viscosity by $253 \%$ by adding $0.2 \% \mathrm{MgO}$ to the water-based mud with a $6 \%$ bentonite mixture [11]. From our laboratory, graphene oxide produced from Spent Pot Lining (SPL) treatment results in better lubricity and rheological values than commonly used commercial additives.

Bingham and power law modelling is widely accepted and used in oil and gas drilling. The Bingham plastic model provides a simple explanation, but cannot represent drilling with low drilling fluid flow and fluids with high shear rates in bits [12]. The Bingham plastic model assumes a linear relationship between the shear rate and the shear stress of the fluid. However, based on measurement data, it is difficult for this to happen. A better representation can be a logarithmic relationship, based on the power law model [12].
Rheological analysis with Bingham and power law models is conducted to show the fluid properties based on the measurement values of the properties of each additive. A torque simulation is required to overcome the frictional forces that occur between the bits and the wellbore wall. Loss of torque can lead to reduced depths of drilled wells [13]. Tension limit simulation needs to be conducted on the drilling process to establish whether the load is within the safe limits of the tool's ability to withstand loads. This is very important to prevent the occurrence of permanent deformation. Control of ECD is very important, because if it is too high it can cause loss of circulation, and if too low can cause kick [14]. Therefore, it is necessary to simulate ECD to establish that the well type is suitable for each of the drilling fluid additives studied in this research.

The aim of this research is to investigate the use of nanomaterials (graphene, $\mathrm{GO}$ and $\mathrm{MgO}$ ) as drilling mud additives in the oil and gas industry. Therefore, research has been conducted on additives that can be used for water-based mud, making it equal or even superior in quality to oil-based mud. Water based drilling fluids are sensitive to formation, promote clay swelling and hydration, thus it is environmental friendly and low-cost $[4,15]$. The technology review includes analysis of mud rheological values using the Bingham parameter method and power law parameters, torque simulation, tension limit simulation, and equivalent circulation density (ECD) simulation of each of the drilling mud fluid additives. Bottom hole pressure resulting from friction occurring in annulus holes plus hydrostatic pressures is also called ECD.

\section{Experimental}

Current research and development in the utilisation of nanomaterials (graphene oxide, graphene and $\mathrm{MgO}$ ) as additive substances to fluid drilling mud. Therefore, study of the technology associated with the use of nanomaterials as additives to drilling mud fluid is the subject of this research. The torque limits and tension limits were determined using the Well Plan software.

\subsection{Types and sources of data}

The type of data used in the study is secondary, obtained from various journals and data companies selling additives. Technological studies conducted include mud rheological analysis with the Bingham plastic method and power law model; torque and tension limit simulation with Well Plan software, and ECD calculation. Table 1 shows the types and sources of data used. 
Table 1. Type and Source of Data

\begin{tabular}{|c|c|}
\hline Type of Data & Data Source \\
\hline $\begin{array}{c}\text { Formulation Data of Drilling } \\
\text { Mud + Ester/Graphene }\end{array}$ & \\
\hline $\begin{array}{c}\text { Rheological Data of Drilling } \\
\text { Mud+ Ester/Graphene }\end{array}$ & \\
\hline $\begin{array}{c}\text { Formulation Data of Drilling } \\
\text { Mud+ Graphene/MgO }\end{array}$ \\
\cline { 1 - 1 } $\begin{array}{c}\text { Rheological Data of Drilling } \\
\text { Mud+ Graphene/MgO }\end{array}$ \\
\hline $\begin{array}{c}\text { Formulation Data of Drilling } \\
\text { Mud+ Graphene } \\
\text { Oxide/commercial additive }\end{array}$ \\
\hline $\begin{array}{c}\text { Rheological Data of Drilling } \\
\text { Mud+ Graphene } \\
\text { Oxide/commercial additive }\end{array}$ \\
\hline
\end{tabular}

\subsection{Research variables}

Independent variables are variables whose values vary in research, while dependent variables are variables whose values are influenced by changes in the independent variable. Table 2 details the independent and dependent variables used in the study.

Table 2. Independent and Dependent Variables

\begin{tabular}{|c|c|c|}
\hline No. & $\begin{array}{l}\text { Independent } \\
\text { Variable }\end{array}$ & Dependent Variable \\
\hline \multicolumn{3}{|c|}{ Processing of mud + graphene formula data } \\
\hline \multirow{4}{*}{1.} & \multirow{4}{*}{$\begin{array}{l}\text { Percentage of } \\
\text { graphene product }\end{array}$} & - Composition of mud \\
\hline & & $\begin{array}{l}\text { - Value of rheological } \\
\text { properties }\end{array}$ \\
\hline & & $\begin{array}{l}\text { Value of torque \& } \\
\text { tension limit }\end{array}$ \\
\hline & & - Value of ECD \\
\hline \multicolumn{3}{|c|}{ Processing of mud + graphene $/ \mathrm{MgO}$ formula data } \\
\hline \multirow{4}{*}{2.} & \multirow{4}{*}{$\begin{array}{l}\text { Percentage of } \\
\text { graphene } / \mathrm{MgO} \\
\text { product }\end{array}$} & - Composition of mud \\
\hline & & $\begin{array}{l}\text { - Value of rheological } \\
\text { properties }\end{array}$ \\
\hline & & $\begin{array}{l}\text { Value of torque \& } \\
\text { tension limit }\end{array}$ \\
\hline & & - Value of ECD \\
\hline
\end{tabular}

Processing of mud + graphene oxide/commercial additive

\begin{tabular}{|l|l|l|}
\hline \multirow{2}{*}{3.} & $\begin{array}{l}\text { Percentage of } \\
\text { graphene } \\
\text { oxide/commercial } \\
\text { additive product }\end{array}$ & $\begin{array}{l}\text { - Composition of mud } \\
\text { - Value of rheological } \\
\text { properties }\end{array}$ \\
\cline { 3 - 3 } & - Value of ECD \\
\cline { 3 - 3 } & - Valon limit \\
\hline
\end{tabular}

\subsection{Mud formula}

Three different mud formulas are used, based on three previous experiments. The first mud formula is a base sugamine formula without additive, compared to the base formula added graphene [10]. The second is a slurry-added mud formula compared to a $\mathrm{MgO}$ added mud formula [11], while the third is a base sugamine formula without additive compared to the base formula plus graphene or commercial additives. Table 3 shows the first mud formula data with drilling mud fluid additives, using graphene with a concentration of $17.5 \mathrm{~mL}$ [10].

Table 3. Mud formula of $10 \mathrm{lb} /$ gal salt polymer mud [16]

\begin{tabular}{|l|c|}
\hline \multicolumn{1}{|c|}{ Product } & Concentration \\
\hline Fresh Water & 302.86 \\
\hline Sodium Carbonate & 0.5 \\
\hline Vacuum Salt & 93.99 \\
\hline Low Viscosity Polyanionic Cellulose & 1.5 \\
\hline $\begin{array}{l}\text { Regular Viscosity Polyanionic } \\
\text { Cellulose }\end{array}$ & 0.5 \\
\hline Xanthan Gum & 1.15 \\
\hline Sodium Hydroxide & 0.5 \\
\hline Drill Solid & 20 \\
\hline Ester Lube/Graphene Lube (mL) & 17.5 \\
\hline
\end{tabular}

The following is a mud formula with a graphene additive or $\mathrm{MgO}$ with varying concentrations [11]. 
Table 4. Concentration of additive substances used for the formula [11]

\begin{tabular}{|l|c|c|c|c|c|}
\hline \multirow{2}{*}{ Composition } & \multicolumn{5}{|c|}{ Concentration } \\
\cline { 2 - 6 } & 1 & 2 & 3 & 4 & 5 \\
\hline Weight (g) & 0.02 & 0.05 & 0.2 & 0.5 & 0.8 \\
\hline Bentonite (g) & 22.5 & 22.5 & 22.5 & 22.5 & 22.5 \\
\hline Graphene/MgO (\%) & 0.005 & 0.01 & 0.05 & 0.1 & 0.2 \\
\hline
\end{tabular}

Table 5 shows the first mud formula data with drilling fluid additives using graphene oxide or a commercial additive [17].

Table 5. Water-Based Mud Formula

\begin{tabular}{|l|c|}
\hline \multicolumn{1}{|c|}{ Material } & Weight (gr) \\
\hline Water & 319 \\
\hline UNIGEL (Bentonite) & 6 \\
\hline KOH & 0,6 \\
\hline KCl Min.97\% & 34 \\
\hline DIAZO VISPOL & 1.7 \\
\hline ARBECEL PAC LV & 4 \\
\hline UNISTARCH & 4 \\
\hline $\begin{array}{l}\text { Commercial additive /Graphene } \\
\text { oxide }\end{array}$ & 2.4 \\
\hline UNIBAR & 26 \\
\hline
\end{tabular}

\section{Results and discussion}

In the research, there are three main evaluations: mud rheological analysis, torque and tension limit simulation, and ECD simulation.

\subsection{Graphene rheological analysis}

Graphene is a two-dimensional material that is the base for all graphitic materials. It is formed from a sheet of carbon atoms with hexagonal cells [18] and is hundreds of times stronger than steel, with indigo voltage of $130 \mathrm{GPa}$. It has a melting point value of $4,237^{\circ} \mathrm{C}[19]$.

The calculation of drilling mud rheological follows the rheological models of Bingham plastic, power law, and modified power law. Bingham plastic is a calculation of rheological mud drilling properties with a simple model for non-Newtonian fluids. A non-Newtonian fluid is defined as one having different viscosities, depending on the shear rate. Unlike a Newtonian fluid, which has a constant viscosity, a non-Newtonian fluid exhibits a yield stress - a certain amount of internal resistance that must be provided for the fluid to flow entirely.

\subsubsection{Rheological analysis of graphene}

Figure 1 shows mud rheological analysis using the Bingham model method on the first mud formula; i.e. that using the base mud and graphene formulas as drilling mud fluid additives. Figure 1 shows that plastic viscosity and yield strength change significantly compared to the base mud formula. This means that the first mud formula has high electrostatic power and better ability to lift the cutting than graphene.

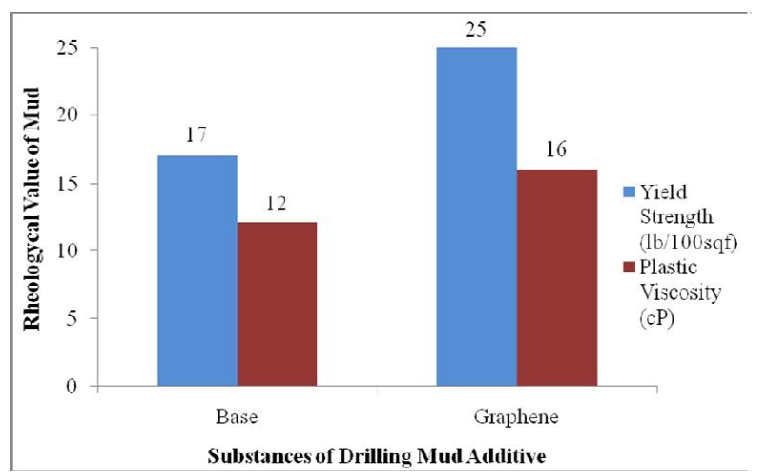

Fig.1. Bingham parameter of base mud formula and graphene

Figure 2 shows the mud rheological analysis using the power law model method. Based on Figure 2 the power law index (n) for graphene slightly decreases compared to the base mud formula power law index (n). This decrease indicates that it is a pseudo plastic. However, there is a considerable increase in the consistency index $(\mathrm{k})$, where the value of $\mathrm{k}$ increases by $39.2 \%$ compared to the base mud formula $\mathrm{k}$. 


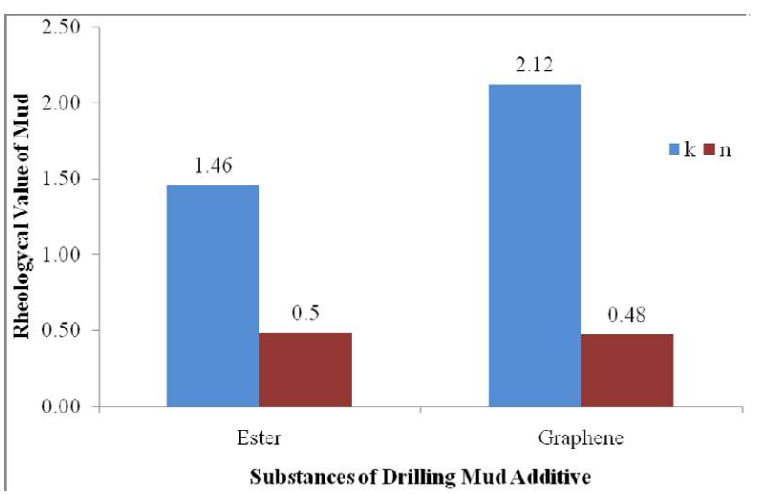

Fig.2. Power law parameters of base mud formula and graphene

\subsubsection{Rheological analysis of $\mathrm{MgO}$ and graphene}

Figures 3 and 4 below show the mud rheology of the second mud formula, i.e. the mud formula using graphene and $\mathrm{MgO}$ with various concentrations. Rheological mud analysis using the Bingham model shows the plastic viscosity from graphene tends to be stable and the addition of the graphene concentration does not affect the value of plastic viscosity of the mud formula with the graphene additive. Therefore, a high concentration of graphene is not necessary to obtain plastic viscosity. The addition of $\mathrm{MgO}$ in various concentrations shows the rise and fall of the value of plastic viscosity of the mud formula with the $\mathrm{MgO}$ additive. The $\mathrm{MgO}$ concentration does not show stability and tends to be difficult to predict.

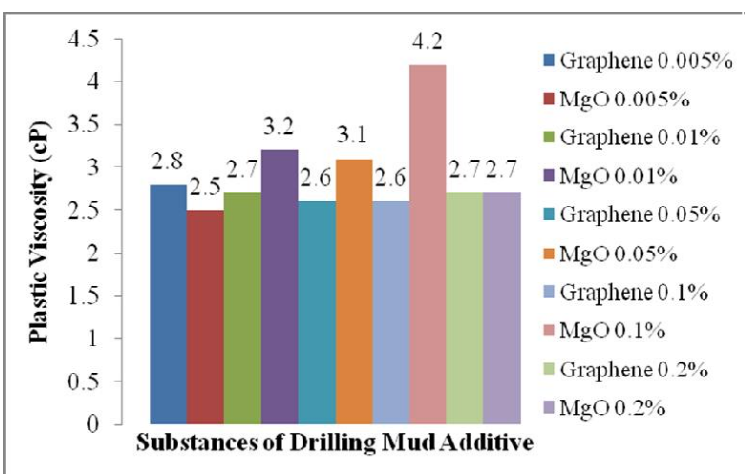

Fig. 3. Plastic viscosity of $\mathrm{MgO}$ and graphene mud formula with various concentrations using the Bingham parameter method.

Based on Figure 4, $\mathrm{MgO}$ has higher yield strength than graphene, so cannot be used as a drilling mud additive, although other rheological values are better than graphene. No analysis is made of the power law method, torque and ECD for mud with $\mathrm{MgO}$ as the drilling mud additive.

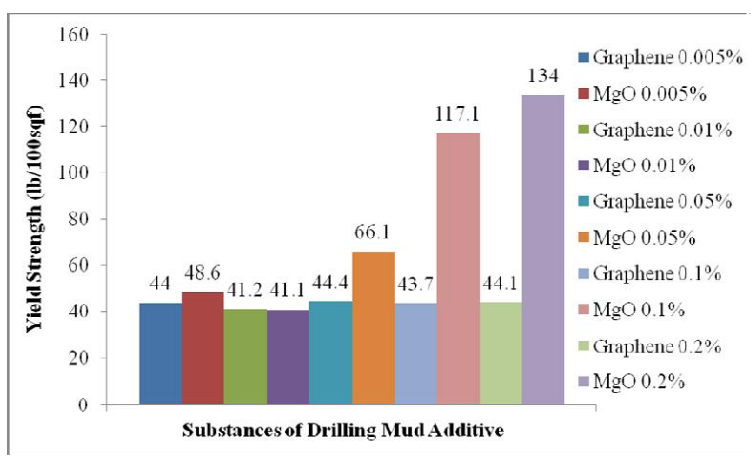

Fig. 4. Yield strength of $\mathrm{MgO}$ and graphene mud formula with various concentration using the Bingham parameter method

\subsubsection{Rheological analysis of graphene oxide (GO) and commercial additive}

Further mud rheological analysis used the base mud formula, commercial additives and graphene oxide as drilling mud fluid additives. Figure 5 shows the mud rheological analysis using the Bingham model method. Based on these figures, the plastic viscosity of the base formulas and commercial additives do not differ much and tend to be almost the same, while the oxene-based mud graphene shows significant changes. This shows that the flow resistance of graphene oxide is lower than the base mud formula. The yield strength of the graphene oxide increases by $180 \%$ compared to the base mud formula, which demonstrates high electrostatic power.

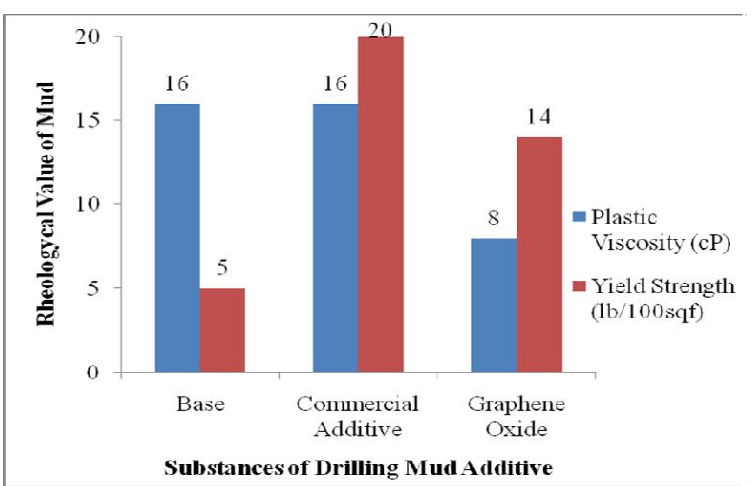

Fig.5. Bingham parameter of base mud formula, commercial additive, and graphene oxide.

Figure 6 shows the mud rheological analysis using the power law method. The value of the commercial additive $\mathrm{n}$ slightly increases compared to the power law index (n) value for the base. Furthermore, the value of the power law index (n) for the GO decreases slightly compared to the $n$ value for the base. This decrease in $n$ values indicates the nature of pseudo plastic. However, there is a considerable increase in the consistency index (k) value; the value of $\mathrm{k}$ on the commercial additive increases by $55 \%$ and on the GO increases by $59 \%$ compared to the base formula $\mathrm{k}$ value. 


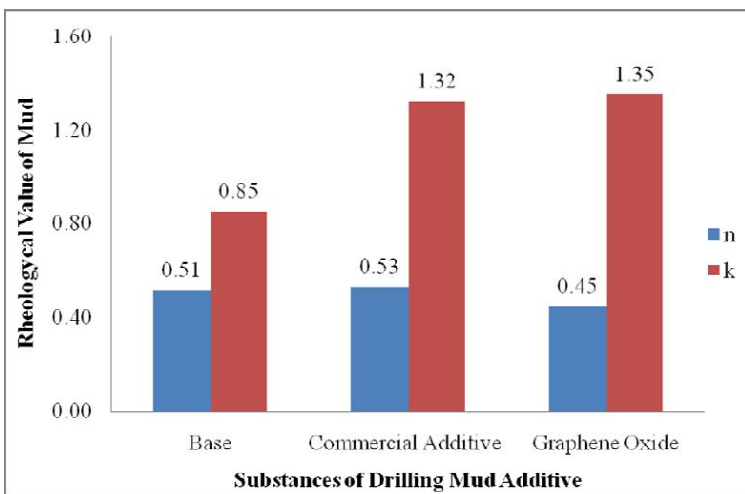

Fig.6. Power law parameter of base mud formula, commercial additive and graphene oxide

\subsection{Torque and tension limit simulation}

Torque and drag are some of the most important elements in the drilling process, especially for sloped wells. If the value of torque and tension limits are too large, then this can cause pipe failure in the drilling process. Torque is the moment needed to play the bits, while drag is the burden required to be able to pull and move the pipe in the wellbore [14].

\subsubsection{Torque and tension limit simulation of graphene}

The tension limit increases with the addition of graphene, compared to the base mud formula (see Fig. 7). For the torque values, the base and graphene mud formulas are not very different, and the depth that can be drilled by using the graphene additive increases. This shows that the addition of graphene has more impact than the base mud formula.

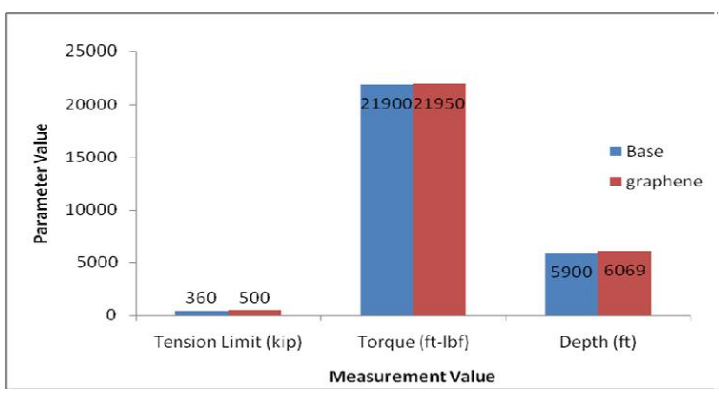

Fig. 7. Parameter values against measurement parameters in grade base and graphene additive formula

\subsubsection{Torque and tension limit simulation of graphene oxide}

Figure 8 shows the effect of the base mud formula, commercial additives and GO on the tension limit, torque and depth. The tension limit increases by $2.11 \%$ with the addition of commercial additives compared with the base mud formula. However, there is a decrease in the tension limit of $2.11 \%$ with the addition of GO compared with the base mud formula. The value of torque, base, commercial additive and graphene oxide do not differ greatly from the base mud formula. The drilling depth using commercial additives increases by $1.8 \%$ compared to the base mud formula. In addition, the addition of graphene oxide additives adds $2.08 \%$ to the of the base mud formula, to $5,921 \mathrm{ft}$. From the above parameters, it can be concluded that the addition of commercial additive has a greater impact than the base mud and mud GO additive formulas. However, the addition of GO can give better results than the base mud formula.

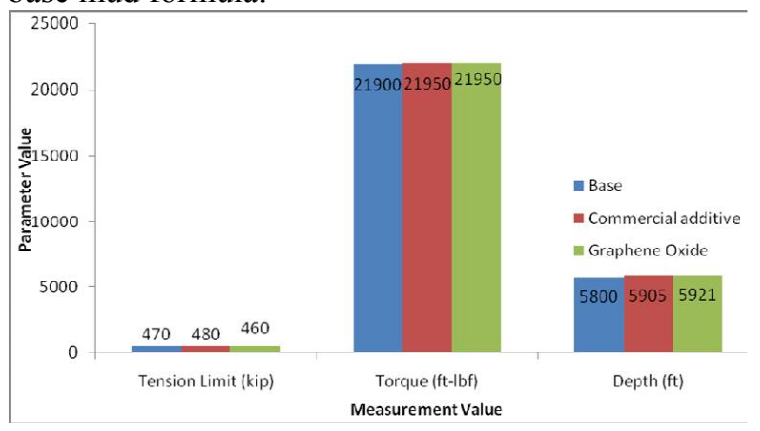

Fig. 8. Parameter values against parameters of measurement in the base mud formula, commercial additive and $\mathrm{GO}$ additive.

\subsection{ECD simulation}

The next simulation was that of ECD. ECD simulation was performed using Excel calculations, with varying flow rates ranging from $5 \mathrm{gpm}$ to 600 gpm. The output of this simulation is the ECD graph of the flow rate.

\subsubsection{Equivalent circulation density simulation of graphene}

The use of graphene produces higher ECD values than the other substances (see Fig. 9). The different ECD values between the base mud and graphene formulas show the stability of each formula. From these results, graphene is more suitable for wells with high formation pressure, because the ECD value tends to be higher than the base mud formula. In such wells, the utilisation of graphene can reduce the risk of kick. The base mud formula is suitable for wells with lower formation pressure so as to reduce the risk of loss of circulation. 


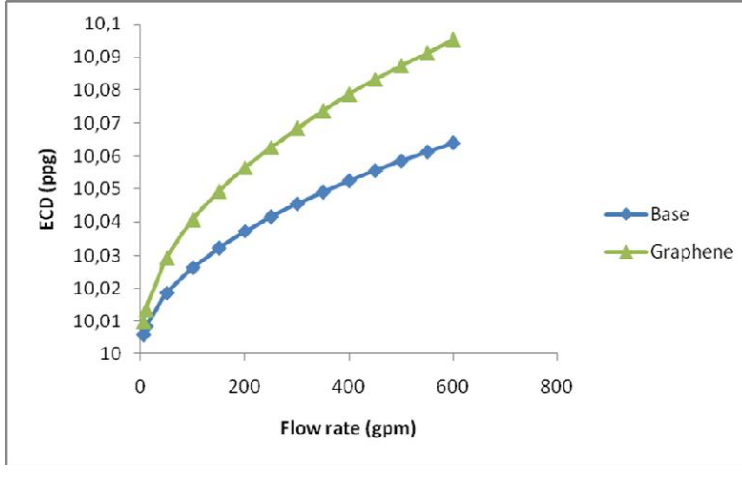

Fig. 9. Flow rate vs ECD of graphene

\subsubsection{Equivalent circulation density simulation of commercial additive and graphene oxide}

The next ECD simulation was performed using the base mud formula, commercial additives and GO. The use of GO as an additive shows results that do not greatly vary with the mud base formula, while the use of commercial additives produces higher ECD values than the other substances (see Fig. 10) The different ECD values between the base mud formula, commercial additives and GO show the stability of each formula. From these results, commercial additives are more suitable for wells with high formation pressures, because the ECD values tend to be higher than the base and graphene oxides. In such wells, the use of commercial additives can reduce the risk of kicking. The base and oxide mud formulas have ECD values that are very similar; both are suitable for wells with lower formation pressures in order to reduce the risk of loss of circulation.

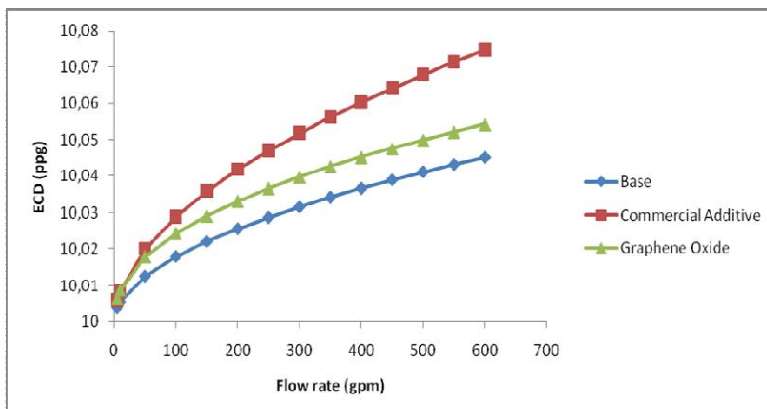

Fig. 10. Flow rate vs ECD of base mud formula, commercial additive and graphene oxide

\section{Conclusion}

Based on this study it is found that in the Bingham parameters, the values of plastic viscosity and yield strength of the graphene additive increased by 25 and $32 \%$, respectively compared to the base formula. The $\mathrm{MgO}$ yield strength value is too high, indicating that $\mathrm{MgO}$ cannot be used as a drilling mud fluid additive. In the graphene oxide additive there was a decrease in plastic viscosity of $50 \%$ compared to the base, indicating the ability to lift the cutting tends to be low, while the yield strength value increased by $180 \%$, which indicates high electrostatic power. The power law parameter values of graphene and GO decreased, showing the nature of pseudo plastic. The graphene torque limit value increased by $0.2 \%$ and drilling depth increased by $2.8 \%$ compared to the base formula. The GO torque limit value increased by $0.2 \%$ and drilling depth increased by $2.08 \%$ from the base formula. The tension limit of the graphene additive increased by $38.8 \%$ compared to the base formula, and that of GO decreased by $2.11 \%$ compared to the base formula. From the ECD simulation, graphene is more suitable for wells with high formation pressure than the base formula. GO is more suitable for wells with low formation pressure than the commercial additives used in mud formulas with commercial additives and graphene oxides.

The authors greatly acknowledge the Indonesian Government for research grant award through PTUPT grant No. 493/UN2.R3.1/HKP05.00/2018.

\section{References}

[1] M. I. Abdou, A. M. Al-Sabagh, Hany El-Sayed Ahmed, A. M. Fadl, Egyptian Journal of Petroleum, In press, (2018).

[2] S. Gautam, C. Guria, D.K. Rajak, A.K. Pathak, Journal of Petroleum Science and Engineering, 166, $63-72$ (2018).

[3] N. Neubergera, H. Adidharmaa, M. Fan, Journal of Petroleum Science and Engineering167, 152-159 (2018).

[4] A. Aftab, A.R. Ismail, Z.H. Ibupotod, H. Akeiber, M.G.K. Malghani, Renewable and Sustainable Energy Reviews 76, 1301-1313 (2017).

[5] N.S. Al-Zubaidi, A.A. Alwasiti, D. Mahmood, Egyptian Journal of Petroleum 26, 811-818 (2017).

[6] C. Karaguzel, T. Cetinel, F. Boylu, K. Cinku, M.S. Celik. Appl. Clay Sci, 48, 398 (2010).

[7] K. Cinku, F. Karakas, F. Boylu, Physicochem. Probl. Miner. Process. 50(2), 453-466 (2014)

[8] G.R. Alther, Engineering Geology 23, 17-191 (1987).

[9] A. Obut, I. Girgin. Madencilik. 44(2), 17-24 (2005).

[10] N.M. Taha, S.L. Lee, Nano Graphene Application Improving Drilling Fluids Performance, International Petroleum Technology Conference, 6-9 December, Doha, Qatar, 2015.

[11] Mahmood, D., Al-Zubaidi, N.S., Alwasiti, A.A. Engineering and Technology Journal 35, 1034- 1041(2017).

[12] M.V. Ochoa, Analysis of drilling fluid rheology and tool joint effect to reduce errors in hydraulics calculations, Dissertation, Texas A\&M University, (2006).

[13] Belayneh, M. Drill string mechanics with a special focus on buckling. Compendium in the 
PET525 class University of Stavanger, Rogaland. (2014).

[14] Forthun, S. Charlotte. Effect Of Nano Additives On Friction In A Bentonite Water Based Sgel strengthtem. (2016)

[15] N.A. Sami, Egyptian Journal of Petroleum 25, 453-458 (2016)

[16] J.V. Taboada, M. Belayneh. Well engineering simulation (Wellplan ${ }^{\mathrm{TM}}$ ) challenges and uncertainties in drilling engineering. Compendium in the PET525

[17] O. Sakadewa, Synthesis of graphene oxide by Hummers and Modified Hummers Methods as Additive drilling Fluids, Final project, Universitas Indonesia (2018).

[18] M.I. Katnelson. Graphene carbon in two dimension (1st ed.). New York: Cambridge University Press. (2012).

[19] M.B Agonafir, S. Wrobel, International Journal of NanoScience and Nanotechnology. 8 (1), 59-71 (2017) 